\title{
建筑施工技术及其现场施工管理
}

胡训峰

连云港市赣榆区建筑工程质量监督站

DOI:10.32629/ems.v2i1.556

[摘要] 随着施工技术逐渐向现代化转变,我们也应该更注重有利于施工过程中的技术问题。众所周知,建筑工程是 一项工程基数庞大,应用技术广泛的综合性施工过程。因此,为了提高施工技术,提升施工效率,保证施工质量,我们需 要对建筑工程现代化施工方面进行着重研究, 本文将对如何进行管理与施工技术这两大内容进行具体分析。

[关键词] 建筑施工; 施工技术; 施工管理

\section{1 施工过程中管理与施工技术的重要性}

随着我国经济水平不断迈向更高台阶, 科学技术不 断进步, 我们知道, 若想不被时代遗弃, 重要的是加强技 术创新, 顺应时代潮流发展, 积极接受新事物并应用于 实践。相比于没有完善管理体制, 缺乏管理的传统建筑 施工, 我们要做的是采用专业化, 规范化体制, 合理分 配, 使有技术的人得到重用, 减少管理层次的级别。传统 建筑工程的管理级别多, 但大多是虚职, 没有分配实际 任务, 导致吃饭的人多, 干活的人少, 造成的结果便是建 筑效果差, 所用时间长, 质量不佳。通过在施工过程中实 行管理与施工技术并行, 能够有效促进施工项目进行。 将责任落实到个人, 可以最大程度的避免施工过程中频 频出现的小问题, 也可规避一些较大问题。即使出现不 可解决问题, 也有相应的管理人员及时处理损失, 使利 益达到最大化。通过引人企业对建筑工程进行管理, 加 大现场施工管理效力, 只有提高自身能力, 才能在激烈 的市场竞争中拔得头筹。同时拥有良好的企业文化, 可 以帮助企业在行业中树立良好形象, 为今后的发展和所 得收益提供保障。

分析。

\section{4 结束语}

总而言之,由于生活质量的提高让广大消费者对房 租经济性与美观性的追求变得更注重, 其中对房屋建筑 成本影响较大的就是房屋建筑结构设计者方面 ${ }^{[3]}$ 。所以 要在房屋建筑的质量上对房屋建筑技术进行优化, 最大 限度的保障消费者的各种需求, 由此可以达到既满足客 户需求方面的要求有可以为公司最大限度的实现经济 效益, 这就是两者完美的结合, 设计人员除了上边叙述 的有效途径以外, 其中对细节还有微小部件的技术优化 也同样是不可忽视的一方面, 所谓说细节决定成败, 忽 略小的细节会给整体房屋建筑带来不好的影响, 一个房 屋建筑结构设计中的技术应用优化是有标准的, 并不是 随意的, 建筑商不能只为了最大程度降低造价成本而对

\section{2 建筑工程施工技术分析}

2.1 建筑中地基施工技术

地基的稳固是整个上层建筑的基础, 通过详细全面 地了解勘察被施工地区的地质情况, 再设计施工地区地 基建设方案, 关键一步就是运用地基施工处理技术确保 地基稳固。一般来说, 由于地基需要承载上层建筑, 因 此, 在地基施工时地基本身的支撑能力也必然为考虑的 重中之重, 然而地基既要打的牢, 又要打的稳并不是一 件简单的事情。地基是否稳固与建筑物所在区域的地质 有关, 我国国土面积辽阔, 各个地区土壤情况不尽相同, 因此需要根据复杂情况进行判断并处理, 常见的土壤处 理方式有: 化学原料加固, 换土加固, 注浆等。拿普遍情 况较多的软地基举例说明: 由于含水量较大, 导致的地 基土质松软, 这便称为软地基, 对于这种松软缺乏地基 支撑力的土壤来说, 我们会对其进行基本处理, 普遍采 用注浆, 即使用经化学原料进行人工合成的泥浆与原本 土壤进行充分混合, 使土壤整体具有支撑性。另一种常 用技术称为换填法, 即换土加固, 顾名思义, 便是将不符 合所需土壤清除，使土壤具有足够支撑力的情况下, 在

房屋建筑优化设计的要求提出改变, 相关企业单位以及 相关的工作人员务必要树立一个正确的技术优化理念, 运用科学合理的方法来优化技术应用,进而为公司实现 工程造价成本的降低, 还同时保障了房屋建筑的居住安 全与质量, 在以后的房屋建筑结构设计优化技术方面的 过程中, 就要从房屋建筑结构设计的多方面角度进行分 析, 综合性的考虑不同影响因素和实现人员、技术平衡。

\section{[参考文献]}

[1]邓超,王涌全,谢静. 结构设计优化在建筑设计中的 应用[J].工程技术研究,2019(15):152+154.

[2]王永强.试析房屋建筑结构设计中的基础设计 [J].建材发展导向,2019(1):70+70.

[3]赵江.优化技术在房屋建筑结构设计中的应用研 究[J].城市建筑,2019(5):105+106. 
地基建设时,逐层将相应土料加人其中,夯实基础, 使稳 定性增强, 以保证能为上层建筑提供足够的支撑力。

\section{2 防水技术}

目前,渗漏问题已经成为检验建筑工程是否合格的 标准之一。大家大概对住了许多年的老房子, 屋顶渗水 类似于这样的事件有所耳闻, 渗漏问题也便成为建筑工 程中的常见问题。家家户户的日常生活均离不开水。由 于建筑工程排水管管道繁多,因此,倘若因使用不当而 造成渗漏问题,我们又应当如何解决呢? 目前建筑工程 会在施工时对易渗漏的位置着重进行防水处理,除此之 外自然因素也不可抗拒, 在雨水多发季节,需要将防积 水这一特性纳人设计中, 墙壁也是不可忽视的一部分。 将防水性能较好的材料加人到施工材料当中, 以确保可 以应对各种渗漏和漏水问题。

\section{3 电气接地技术的普遍应用}

在日常生活中, 电伴随着人们的日常生活。随着我 国人均生活水平不断提高, 科技的不断进步, 家用电器 种类数目得到大幅度提升, 人们在日常生活中选择使用 的电器也越来越多, 在用电背后, 人们更关注的是用电 安全。所以,建筑施工技术考核的重要项目也包括用电 安全。为了保证用电安全, 在施工前要做的准备是优化 设计建筑工程电力线路, 明确规定每个家用电器标准, 在断路器开关选择质量优秀的设备。除此之外, 我们必 须考虑到, 目前高层建筑繁多, 建筑外形也并不单一, 在 雷雨等恶劣天气下, 高层建筑有被雷击的概率。因此在 施工过程中, 应当保证在任何电器出现短路或其他故障 下, 也可以保证整栋建筑的安全性。利用电气接地技术, 可以更好的改善因环境造成的不可抗拒因素, 更大程度 的保证人们的安全。

\section{3 施工技术和管理层次在应用过程中存在的问题}

3.1 由于环境带来的客观因素

环境因素是在实际日常施工过程中,严重影响工期 的因素。在施工过程中, 高温降雨大风等恶劣天气或环 境, 会使施工过程难度大大提升, 可能会导致施工时期 延长或无法进行。客观环境因素, 或许会对所准备好的 建筑材料和设备产生影响, 甚至于损坏。最终会导致工 期无法按时进行, 甚至延期。所以在施工工作进行前, 应 当让专业人员仔细分析该地区的环境天气情况, 做好一 切应对措施, 尚可在意外发生时, 保障施工人员、材料以 及设备的安全, 以保证工作顺利安全进行。

\section{2 由于建筑技术的落后带来的主观因素}

我国地域辽阔, 各个地区发展水平也不同,一些发 达城市和地区拥有先进施工技术和设备, 而偏僻地区少 有先进建筑技术, 也难有高科技设备, 根据当地风俗习 惯始终沿用传统建筑方法, 这给施工造成很大难度。发
达城市可以利用高科技手段和设备高效率完成建筑任 务, 而偏僻地区无法借助外来手段提高效率。国家已经 下发施工标准, 然而, 许多地区缺乏技术手段, 不能够达 到建筑标准, 但又不得不适应社会需要如期交工, 因此 就会导致各种意外的发生。除此之外, 倘若没有先进的 运输技术, 在购买建筑材料时也会时常有缺少原材料的 事情发生, 影响建筑工期如期交工, 甚至会出现安全事 故, 施工人员的安全和整个建筑物的质量也得不到保 证。

\section{4 为建筑工程现场管理向更好发展提出的举措}

4.1 施工过程中人人担责

人是开展建筑工程的基础。在建筑工程现场管理的 具体举措中, 为保障施工任务正常并向更好方向进行, 应当将每个人的陈旧观念进行转变。当每个人的主观能 动性达到最大时, 整个团队的施工效率便可以大大提 高。人人各司其职, 人人担责, 当自己的利益与集体汼扯 时, 一定会付出最大的努力。具体主要分为两个层面: 第 一, 管理阶级。建筑工程的管理人员应当将管理章程烂 熟于心, 严格遵循执行体系, 按时仔细地对建筑施工现 场进行质量监测和安全监督,一旦发现问题, 及时解决, 避免拖沓造成严重后果, 保证施工有序进行。第二, 服从 者。对于施工人员来说, 他们便是服从者, 听从上层安排 指令, 在一定时间内, 在自己岗位上, 按照安排完成自身 工作。施工人员的管理者, 需要保证施工现场有严格的 纪律, 同时兼具活跃的氛围。严格的纪律, 给施工人员施 加压力, 能保证建筑工程有序进行, 活跃的氛围又能积 极调动施工人员的劳动能力, 使他们有动力为整个建筑 工程贡献自己的力量, 赏罚分明。这是一个优秀的施工 团队所具有的基本素质, 管理者言出必行, 服从者积极 响应, 每个人都以严谨态度来对待施工工作, 这样整个 团队工作效率提高, 更有利于建设出优质的建筑物。

4.2 培养施工人员的安全意识和基本素养

只有施工人员的安全素养和自身安全意识得到提 高, 才能使施工过程得到保证, 既稳定人心, 又能更好的 为建筑事业做出贡献。大家大概都见过施工工地门口贴 着 “高高兴兴上班, 平平安安回家” 等一系列类似的宣传 标语, 在施工过程中, 重中之重便是保证施工人员安全, 这样无论是对于施工人员还是对于住户都有利于打造 一个安全的建筑环境。一个施工团队, 如果保障自己每 个团员的权利, 保障安全, 那么将会有更好的发展。同 时, 企业也应当成立专门的安全监管人员, 实时认真仔 细逐项排查工地中的安全隐患, 保障施工人员安全。

\section{3 完善的施工管理体系}

一套完善的管理体系是支撑建筑工程过程顺利开 展的良好保障, 但是在实际的建筑工程施工过程中, 由 


\section{浅析建筑施工中防水施工技术}

李宗满

连云港市赣榆区建筑工程质量监督站

DOI:10.32629/ems.v2i1.557

[摘 要] 建筑施工中的一项难点工作就是渗水漏水问题, 当建筑物出现该问题会对建筑物的质量产生严重的影响, 给后期使用过程中也带来严重的麻烦。建筑工程的防水对建筑安全、人身安全有着直接的影响, 防水技术作为建筑工 程施工技术的一个重要的组织部分,防水技术的良好施工关乎建筑的整体质量,对建筑工程施工具有重要的意义。本 文针对建筑工程施工中防水施工技术的重要意义进行分析, 对当前建筑施工中常见的渗漏问题进行阐述, 进而有针对 性的提出相应的解决对策。

[关键词] 绿色建筑; 工程管理; 问题研究

\section{1 防水施工技术在建筑工程施工中的重要性}

1.1 建筑物的防水关乎使用者的人身安全

建筑物的建设意义就是要后期投入到实际运营,为 人们所使用, 供人们开展生产生活。如果在建筑工程的后 期使用过程中持续发生渗水漏水等问题, 将会导致建筑 物各项材料出现快速损坏、老化, 如果长期如此就会导致 建筑物出现漏电等各种严重的后果。一旦发生这些问题, 就会对使用建筑的人们产生威胁, 威胁人身安全和财产 安全, 从而导致社会不稳定因素的出现。因此, 在建筑工 程施工过程中, 加强对防水技术的应用, 能够有效地保障 建筑的质量,避免影响人身安全的事情发生。

1.2 防水技术是建筑工程施工技术的一项重要组成 部分

防水技术的使用对建筑工程来说十分钟, 其作为建 筑施工的一项重点工作, 成为建筑施工中一项需要专门 注意的专项技术施工。应用防水技术, 能够有效的减少外 部污染物对建筑的腐蚀, 进而推动建筑物使用寿命的延 长。在建筑工程施工中, 需要依托于防水技术的使用保障

于缺乏完善的监督管理体系, 致使在建筑过程中出现了 一系列的问题。在建筑施工过程中, 由于管理体系没有 更好地落实和完善, 并且企业当中的管理层重视程度也 不够, 就会致使工作人员在施工过程中自顾自的进行工 程开展。在一些小型的建筑施工单位, 由于其资金的缺 乏, 以及管理体系的不完善, 导致建筑施工场地没有完 善的安全防范措施。不仅缺乏安全意识, 甚至还有可能 影响到整个团队的协作, 为施工过程造成一定的安全隐 患。

\section{5 结语}

综上所述, 施工技术中包含的工程电气接地技术, 施工防水技术和地基的处理这三方面技术很少有人涉 猎并深人探索, 但这三方面对于现实生活中的施工工程
施工质量,从而为人们日常生活提供一个良好的居住、生 活环境。对于工程施工来说,防水技术已经成为工程施工 的一项重点, 是施工过程中需要重点关注的内容。

\section{3 防水技术关乎建筑工程整体质量}

建筑工程的施工是一项十分复杂的事情, 其涵盖的 内容十分广泛, 涉及的专业技术也相对较多, 这其中每一 个环节施工都成为影响施工质量的一项重点, 任何一个 环节施工的差错都有可能造成严重的后果, 对建筑质量 产生严重的问题。防水技术作为施工中一项重要环节,其 对建筑工程的质量有着严重的后果, 一旦防水工作做不 好,将直接导致后期维护成本直线升高,给维护工作带来 很大的困难。影响建筑物渗水漏水问题的原因有很多, 建 筑材料、施工技术、施工管理等等都成为影响的重要因 素,在这些众多因素中,施工技术对建筑工程质量的影响 是最重要的。

\section{2 绿色建筑工程管理中存在的关键问题}

渗水漏水问题长期以来一直都是建筑物中最为常 见的一项问题,根据相关调查显示, 在建筑施工中屋面、

来说, 具有十分重要的意义和参考价值。因此, 倘若在这 三方面有所突破,将会使施工技术在不同程度上达到一 定水平。除此之外, 为保证施工顺利进行, 就要保证工人 在施工过程中的安全, 由此可见工地现场的管理工作也 同样重要, 将管理与技术并行, 才能够基本保证建筑工 程的顺利进行,

\section{[参考文献]}

[1]杨伟.建筑工程施工技术及现场施工管理 [J].中 外企业家,2020(10):129.

[2]刘志刚. 房屋建筑现场施工技术质量管理的分析 思路 [J].工程建设与设计,2020(05):255+259.

[3]黎洪林. 房屋建筑工程施工技术及现场施工管理 [J].智能城市,2020,6(04):155+156. 